\title{
Risk factors involved in physical child abuse of children from Bihor County
}

\author{
Monica Adriana MOTORCA (BOGOSEL) ${ }^{1,2}$, Camelia Liana BUHAS ${ }^{3,4}$, Flavia Serena SANDOIU ${ }^{4}$, \\ Luca Daniel SANDOIU ${ }^{5}$, Laura Anca LELE ${ }^{1,2}$, Alina Cristiana VENTER ${ }^{3,6}$ \\ ${ }^{1}$ Department of Medical Disciplines, Faculty of Medicine and Pharmacy, University of Oradea, Romania \\ ${ }^{2}$ Department of Pediatrics, "Gavril Curteanu" Municipal Clinical Hospital, Oradea, Romania \\ ${ }^{3}$ Department of Morphological Disciplines, Faculty of Medicine and Pharmacy, University of Oradea, \\ Romania \\ ${ }^{4}$ Forensic Service of Bihor County, Oradea, Romania \\ ${ }^{5}$ Department of Orthopedics and Traumatology, Emergency County Clinical Hospital, Oradea, Romania \\ ${ }^{6}$ Department of Radiology, Emergency County Hospital, Oradea, Romania
}

\begin{abstract}
Introduction. Understanding the risk factors leading to child abuse is useful when developing effective prevention and early intervention strategies.

Modern experts who assessed the environment of the abused child reported that risk factors are multidetermined and are derived from three main etiological causes: parental, ecological and intrinsic problems of the child.

Material and methods. A statistical analysis was performed on a group of 176 cases of reported child abuse in Bihor County between 2013 and 2017. The collected data was examined with the use of SPSS 2.0 statistical program.

Results. Results demonstrate that the most frequent risk factor involved in physical child abuse is alcohol consumption (28.98\% of cases), followed by abuser's nervousness and drug consumption; the least frequent risk factor being abuser's response to property theft.

Discussions. Physical violence can cause both psychological and physical damage to the child. Research shows that when children experience a certain form of violence, they are also associated with a higher risk of being vulnerable to other forms of abuse.

Conclusions. The most frequent risk factor involved in physical abuse of children from Bihor County is alcohol consumption, representing $28.98 \%$ of all risk factors analyzed. A holistic approach is absolutely essential for eliminating physical abuse of children.
\end{abstract}

Keywords: abuse, risk factors, causes

\section{INTRODUCTION}

The World Health Organization lists child maltreatment as one of the most important contemporary public health issues. It defines physical abuse of children as "any intention- al use of physical action against a child that causes or is likely to cause harm to the child's health, survival, development or dignity, including beating, kicking, shaking, biting, strangulation, scalding, burning, deliberate poisoning and suffocation, or failure to prevent physical injury (or suffering)" (1). 
Child abuse in society is a well-known phenomenon and cannot be associated with a certain historical period (2). Over the centuries, children have been killed, beaten, abandoned, forced into labor, sometimes in the name of cultural practices, sometimes simply because of their parents socio-ideology. Unfortunately, until recently, modern society has refused to recognize the magnitude and gravity of this social problem. Only in the last four decades of the last century, the phenomenon has become one of major interest, both for specialists in various disciplines and for the general public. In fact, the first article that brought to the attention of the scientific community the reality and seriousness of parental child abuse was published in 1962 by Henry Kempe (3), an American pediatrician.

Contemporary theoretical models explain child abuse as a complex phenomenon caused by an interaction of multiple factors at different levels: individual, relational, community, and societal.

Modern specialists and experts who assessed the environment of the abused child reported that risk factors related to child abuse practices are multidetermined and are derived from three main etiological causes: parental causes, ecological causes and intrinsic problems of the child.

Generally, two main interacting categories of factors are involved, known as precipitating and compensatory factors of child abuse.

Risk factors for child maltreatment are the measurable circumstances, conditions or events that increase the probability that a family will have poor outcomes in the future. When these factors are combined with limited protective factors, they indicate an increase in the probability of children experiencing abuse.

Protective factors are attributes or conditions that can occur at individual, family, community or wider societal level. Protective factors can moderate risk or adversity and promote healthy development and child and family wellbeing (4).

In other terms, these factors are often interconnected and may have a cumulative effect, thus leading to the assumption that child abuse occurs when risk factors prevail over compensatory ones. Some factors may have a permanent influence, while others may be transient, some may be protective in some combination, or may increase the potential for abuse in association with others (5). The effects of child abuse vary depending on the type of abuse exerted. Some of these effects are physical and others are emotional or psychological. Studies show that physical and emotional abuse has a major impact on the child. Effects can be classified into short-term effects and long-term effects. Several studies confirm a connection between abuse and frequent illnesses in the child in the first year of life. The underlying explanation of this phenomenon is easy to understand: sick children scream more often and are difficult to calm down.

This situation can lead to a perception of excessive demands from the child, followed by feelings of powerlessness and inadequacy in the abuser, who's most common and non-rational response will be to inflict abuse (6).

The spectrum of physical abuse-related risk factors is very broad; however, these assumptions could not be proven empirically. All types of child abuse, regardless of its causes, affect the child in some way (7).

\section{MATERIAL AND METHODS}

This manuscript reviews risk factors for physical abuse in children and comprises part of a much broader research.

The focus of this manuscript is therefore the assessment of physical child abuse in regards to the presence of various risk factors.

More specifically the aim of this study was to identify the main risk factors involved in physical abuse of children from Bihor County and to statistically analyze and compare them.

An analysis was performed on a group of 176 cases of reported child abuse in Bihor County between 2013 and 2017. Data collection was performed by accessing the archives of Bihor County Forensic Medicine Service and reviewing the forensic reports on child abuses.

The entire activity was carried out between August 12, 2016 and October 18, 2017. Regarding the inclusion and exclusion criteria, the inclusion criteria were:

- Children aged between a few months and 18 years

- Children who have a positive diagnosis of physical abuse

- Children from Bihor County

- Cases of physical abuse from 2013 to 2017

- Cases that are permanently registered within Forensic Medicine Service

- People who had a voluntary agreement, written consent before conducting the study-related procedures

- Persons who were eligible to comply with and understand the relevant aspects of the study protocol.

Exclusion criteria were:

- Children over the age limit

- Children with an uncertain diagnosis of physical abuse

- Children outside Bihor County

- Cases excluded from a time interval other than the one referred to in the statistics

- People who risk compromising the quality of the study

- People likely to leave the region

- People eliminated for ethical reasons 
- People whose medical condition, effects and symptoms may alter the suspicion of physical abuse

- Unclarified medical history

- Incapable patients who do not want to respect or understand the entire activity of the study

- Certain life-threatening medical conditions

- Cases with medical evidence and thematic evidence that showed an uncertain positive or negative result.

Thus, a statistical analysis was performed with the help of the SPSS statistical program, version 2.0, through which the frequency in each type of abuse and the relative risks were calculated, followed by category comparison.

\section{RESULTS}

51 people admitted alcohol consumption, which was identified in this study as the most frequent cause of child physical abuse, constituting $28.98 \%$ of all the analyzed cases. This risk factor is followed by abuser's nervousness (24 people representing 13.6\%) and drug consumption (16 people representing $9.1 \%$ of cases). The least frequently encountered risk factor was the abuser's response to property theft by the child (5 people accounting for $2.8 \%$ of cases). In fact, the largest significant difference is between these two categories: people who were under the influence of alcohol and the context based on a theft from the abuser, $(x 2=45.046, p<0.0001)$, with a difference of $26.2 \%$, and also a relative risk of almost 10 times higher for people who consumed alcohol compared to the reason for a theft from the abuser, (RR = 10.35).

Table 1 and the figures 1 and 2 elicit the contexts in which the abuse has occurred and their frequency variation.

TABLE 1. The contexts in which the abuse occurred

\begin{tabular}{|l|c|c|c|c|}
\hline & Frequency & Percent & $\begin{array}{c}\text { Valid } \\
\text { Percent }\end{array}$ & $\begin{array}{c}\text { Cumulative } \\
\text { Percent }\end{array}$ \\
\hline Under influence of alcohol & 51 & 29.0 & 29.0 & 109.0 \\
\hline Under influence of drugs & 16 & 9.1 & 9.1 & 34.2 \\
\hline Under influence of drugs and alcohol & 6 & 3.4 & 3.4 & 12.8 \\
\hline Under influence of mental stress & 16 & 9.1 & 9.1 & 34.2 \\
\hline Moment of nervousness & 24 & 13.6 & 13.6 & 51.2 \\
\hline Negative attitude on the part of the abused person & 9 & 5.1 & 5.1 & 19.2 \\
\hline Nervous abuser following a workplace conflict & 12 & 6.8 & 6.8 & 25.6 \\
\hline Due to the agitation of the abused person & 9 & 5.1 & 5.1 & 19.2 \\
\hline Conflict & 15 & 8.5 & 8.5 & 32.0 \\
\hline Poor learning outcomes & 13 & 7.4 & 7.4 & 27.8 \\
\hline Theft of property from the abuser & 5 & 2.8 & 2.8 & 10.6 \\
\hline Total & 176 & 100.0 & 100.0 & 100.0 \\
\hline
\end{tabular}

FIGURE 1. Graphic representation of risk

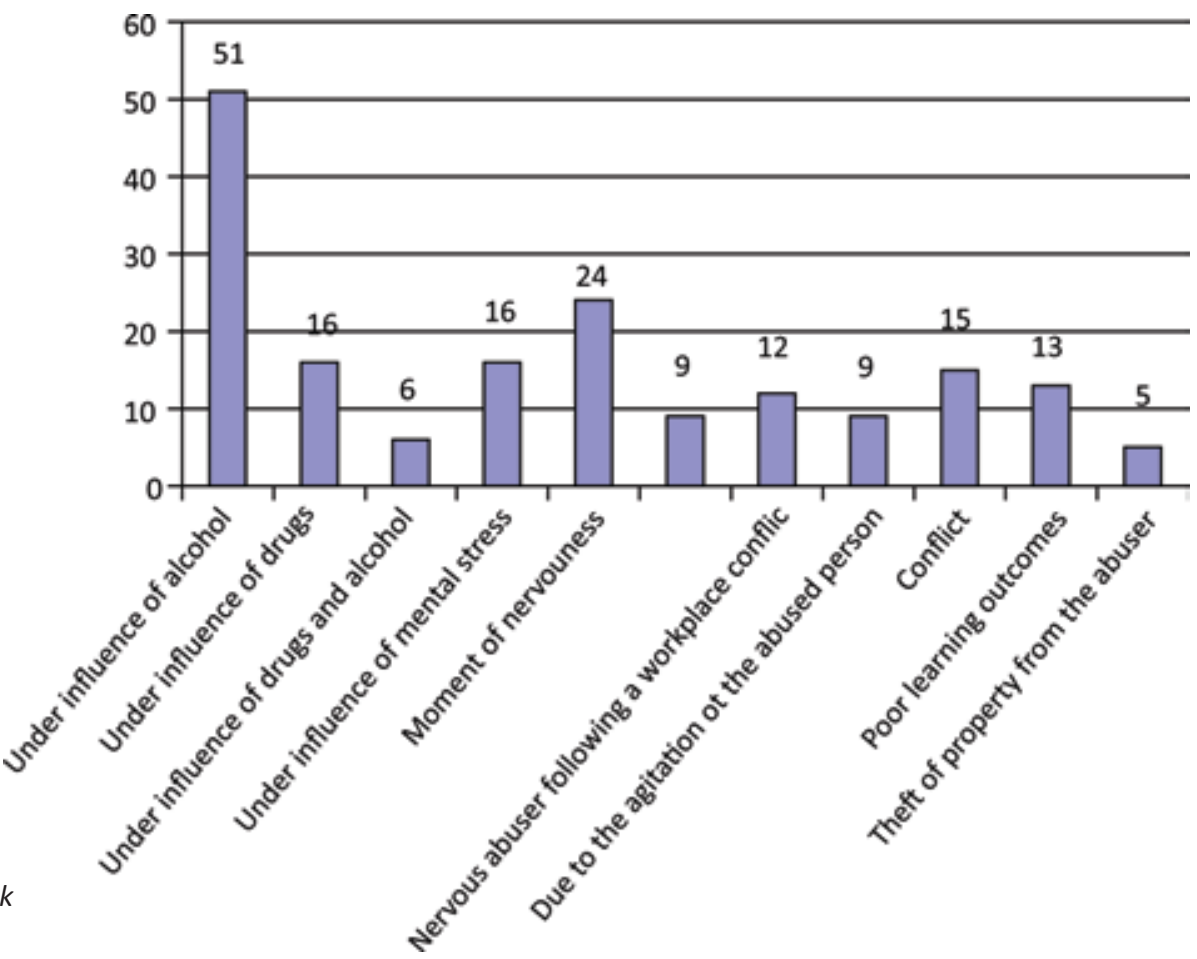




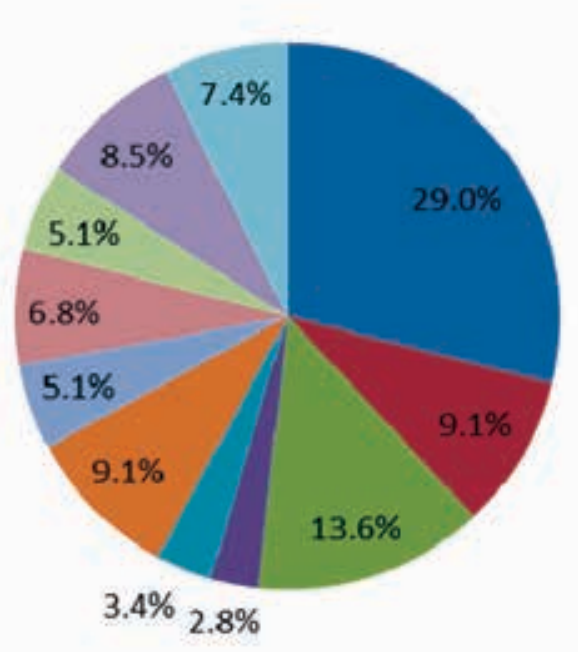

FIGURE 2. Graphic representation of risk factor percentage

\section{DISCUSSION}

As previously introduced, risk factors are intertwined and often exert their effect in a cumulative manner. Therefore a single factor cannot always trigger the act of abuse, while the combination of two or more factors can lead to tragic results.

From the criterion of drug or alcohol use in relation to the abuser, our research places them in first and third position in risk factor frequency, as in concordance with other scientific literature publications $(8,9)$. Consequently it can be concluded that these factors can most often be the cause of physical abuse of children, the mechanism underlying this phenomenon is explicable through the diminished self-awareness induced by drug or alcohol use hence abusers fail to take immediate corrective action or simply are not able to stop when committing violent actions against children (10). Simply put increasing alcohol and drug use among people correlates with the increase in child abuse.

The risk of experiencing a childhood with violence increases when children come from poor families, which in turn increases the risk of being trapped in poverty in adulthood, so delimiting the cause from the actual effect is a challenge $(11,12)$.

If we add up several factors, we can also conclude that mental illness and stress can lead to a large number of child abuses. In fact caregiver's angry and uncontrolled disciplinary response to actual or perceived misconduct of the child has an important role in our study also, considering the fact that abuser's nervousness was ranked in second position in our risk factor frequency assessment.

Beyond the health, social and educational consequences of child maltreatment, there is a vicious cycle problem. In scientific literature a large number of stud- ies have not only shown that alcohol is a significant contributing factor to child abuse, but also demonstrate that physical abuse of a child when alcohol or drugs are involved can lead to increased risk of that same child becoming a drug or alcohol user (13-15).

Regarding the subjects of our study who perpetrated child physical abuses, the number of those who consume alcohol and drugs exceeds those who do not consume; this aspect can be put in the act of abuse. In any worldwide study involving child physical abuse, alcohol consumption is an important factor found strikingly more often than other factors (16).

Nevertheless, the most important aspect depicted in our study is the multifactorial etiology of child physical abuse. Consequently, although the results are in line with other findings in international literature, certain limitations were encountered. It would have been preferable to be able to study a broader lot of cases in order to have a clearer and more accurate view of such social phenomenon. This would have also allowed the discovery of other types of risk factors and the better understanding of how they interact.

The multifactorial nature of physical abuse in children requires a comprehensive model and framework to account more efficiently for the heterogeneous set of risk factors involved in child physical abuse. Also, the study could have benefitted (as well as generally social prevention and outcome could improve) from the implementation of a more detailed and targeted questionnaire through which to acquire the information regarding the abuse/context in which the abuse unfolded.

In terms of prevention of child physical abuse when a person consumes alcohol, an important step would be to reduce alcohol consumption among the population by using media services (TV, internet, newspapers) that can promote various advertising campaigns against alcohol consumption and show its effects, also, its correlation with physical abuse of children as well as 
public awareness, and the fact that a high alcohol consumption can lead to acts of violence and this makes them directly guilty if they are not doing something about it and remain indifferent (17). After analyzing the medical reports and observing the personal details of the abused children and regarding the risk factors of the abusers, it was found an increased prevalence of comorbidities of mental disorders due to alcohol and drug use with other pathological disorders. Factors with an increased risk of triggering various disorders or behavioral changes over time that lead to mental illness, hostility, depression, nervousness, etc., may be represented in the experience of physical child abuse. The effects of physical abuse on the child vary depending on the severity of the injuries suffered. Some of these effects are physical and others are emotional or psychological. Studies show that physical abuse has a major impact on the child and these effects can be classified into short- term effects and long-term effects (18). It is difficult to decipher the consequences of physical abuse on children during childhood by other factors that can negatively affect a person's life (such as poverty or disability) (19). There are clearly interconnections between violence and disadvantage. For this reason, and because violence against children has so many consequences and risk factors, this article has analyzed only a small part of them. However, it is important to remember that the causal link between physical abuse on children and its consequences does not always imply inevitability (20). Each person's response to violence is necessarily unique, and if physical abuse of children can have long- term repercussions, recovery for children is still possible. In essence, these are just a few possible risks of violence against children, and from this brief examination of the effects of violence, it is clear that the negative repercussions are closely interconnected (21). For example, if a child suffers serious harm, he or she is immediately at greater risk of impaired cognitive development, which in turn makes the child more vulnerable to abuse. It is important to emphasize that risk factors related to child abuse practices are multidetermined, therefore, a holistic approach, which involves combating poverty, discrimination and attitudes/habits that allow violence against children to go uninvestigated, is absolutely essential for eliminating physical abuse of children (22).

\section{CONCLUSIONS}

The present study revealed that the most frequent risk factor involved in physical abuse of children from Bihor County is alcohol consumption, representing $28.98 \%$ of all risk factors analyzed. The least involved risk factor is represented by the abuser's response to property theft by the child.

The multifactorial nature of physical abuse in children requires a comprehensive model and framework to account more efficiently for the heterogeneous set of risk factors involved in child physical abuse. Given this premise, it is also obvious that the only efficient way to eliminate this social phenomenon is also a multifactorial-type approach that has to deal not only with the environment of the child but also attitudes/habits that allow that violence to exist in the first place.
Conflict of interest: none declared

Financial support: none declared

\section{REFERENCES}

1. World Health Organization (WHO). European Report on Preventing Child Maltreatment. Copenhagen: WHO Regional Office for Europe, 2013.

2. Wolfe AD. Child Abuse: Implications for Child Development and Psychopathology (2nd Edition). Sage Publications, 1999.

3. Kempe CH, Silverman FN, Steele BF, et al. The Battered Child Syndrome. In: Donnelly AC, Oates K. Classic Papers in Child Abuse. Sage Publications, 2000:10-25.

4. Pace GT, Lee SJ, Grogan-Kaylor A. Spanking and young children's socioemotional development in low- and middle-income countries. Child Abuse Negl. 2019;88:84-95.

5. Preventing Child Maltreatment: a Guide to Taking Action and Generating Evidence. World Health Organization and International Society for Prevention of Child Abuse and Neglect. 2006:12-23.

6. Gherguţ A. Evaluare şi intervenţie psiho-educaţională: terapiile educaţionale, recuperatorii şi compensatorii. Iași: Editura Polirom, 2011:10-98.

7. Graham RA, Weems CF. Identifying Moderators of the Link Between Parent and Child Anxiety Sensitivity: The Roles of Gender, Positive Parenting, and Corporal Punishment. J Abnorm Child Psychol. 2015;43(5):885-93.

8. National Institute for Health and Care Excellence. When to Suspect Child Maltreatment. 2009. Available at: www.nice. org.uk/CG89 (accessed 23 November 2011).

9. Sheikh MA, Abelsen B, Olsen JA. Clarifying Associations between Childhood Adversity, Social Support, Behavioral Factors, and Mental Health, Health, and Well-Being in Adulthood: A Population-Based Study. Front Psychol. 2016;7:727.

10. Walsh K, Latzman NE, Latzman RD. Pathway from child sexual and physical abuse to risky sex among emerging adults: the role of trauma-related intrusions and alcohol problems. J Adolesc Health. 2014;54(4):442-8.

11. Dutcher CD, Vujanovic AA, Paulus DJ, Bartlett BA. Childhood maltreatment severity and alcohol use in adult psychiatric inpatients: the mediating role of emotion regulation difficulties. Gen Hosp Psychiatry. 2017:42-50

12. Wang $L$, An CX, Song M, et al. Evaluation of childhood traumatic experience as a risk factor for alcohol use disorder in adulthood. BMC Psychiatry. 2020;20(1):15.

13. Hiller RM, Meiser-Stedman R, Fearon P, et al. Research Review: Changes in the prevalence and symptom severity of child posttraumatic stress disorder in the year following trauma - a meta-analytic study. J Child Psychol Psychiatry. 2016; 57(8):884-98.

14. Goldberg AE, Blaauw E. Parental substance use disorder and child abuse: risk factors for child maltreatment?. Psychiatry, Psychology and Law. 2019; 26(6):959-969. 
15. Mandavia A, Robinson GGN, Bradley B, et al. Exposure to Childhood Abuse and Later Substance Use: Indirect Effects of Emotion Dysregulation and Exposure to Trauma. J Trauma Stress. 2016;29(5):422-429.

16. Kennedy SC, Kim JS, Tripodi SJ, et al. Does Parent- Child Interaction Therapy Reduce Future Physical Abuse? A Meta-Analysis. Research on Social Work Practice. 2016;26:147-156.

17. Landsford JE, Godwin J, Uribe Triado LM, et al. Individual, family, and culture level contributions to child physical abuse and neglect: A longitudinal study in nine countries. Dev Psychopathol. 2015; 27(4 Pt 2):1417-28.
18. Litrownik AJ, Newton R, Hunter WM, et al. Exposure to family violence in young at-risk children: A longitudinal look at the effects of victimization and witnessed physical and psychological aggression. J Family Violence. 2003;18:59-73.

19. Overbeek M, de Schipper J, LamersWinkelman F, et al. Risk factors as moderators of recovery during and after interventions for children exposed to interparental violence. Am J Orthopsychiatry. 2014;84:295-306.

20. Kemp K, Signal T, Botros H, et al. Equine facilitated therapy with children and adolescents who have been sexually abused: a program evaluation study. J Child
Fam Stud. 2013;23:558-66.

21. Mihalache G, Buhaş C, Rahotă D. Medical and social implications of suicide in youth. Holistic study of cases in Bihor county 2007 - 2009. Rom J Leg Med. 2011;19(1):69-72.

22. Stoltenborgh M, Bakermans Kranenburg M, ljzendoorn M, et al. Cultural-geographical differences in the occurrence of child physical abuse? A meta-analysis of global prevalence. Int J Psychology. 2013. 48(2):81-94. 